\title{
Withdrawal from cocaine self-administration produces long-lasting deficits in orbitofrontal-dependent reversal learning in rats
}

\author{
Donna J. Calu, ${ }^{1}$ Thomas A. Stalnaker, ${ }^{2}$ Theresa M. Franz, ${ }^{2}$ Teghpal Singh, ${ }^{1}$ \\ Yavin Shaham, ${ }^{4}$ and Geoffrey Schoenbaum ${ }^{2,3,5}$ \\ ${ }^{1}$ Program in Neuroscience, University of Maryland School of Medicine, Baltimore, Maryland 21201, USA; ${ }^{2}$ Department \\ of Anatomy and Neurobiology, University of Maryland School of Medicine, Baltimore, Maryland 21201, USA; ${ }^{3}$ Department \\ of Psychiatry, University of Maryland School of Medicine, Baltimore, Maryland 21201, USA; ${ }^{4}$ Behavioral Neuroscience Branch, \\ Intramural Research Program, National Institute on Drug Abuse/National Institutes of Health/Department of Health and Human \\ Services, Baltimore, Maryland 21224, USA
}

\begin{abstract}
Drug addicts make poor decisions. These decision-making deficits have been modeled in addicts and laboratory animals using reversal-learning tasks. However, persistent reversal-learning impairments have been shown in rats and monkeys only after noncontingent cocaine injections. Current thinking holds that to represent the human condition effectively, animal models of addiction must utilize self-administration procedures in which drug is earned contingently; thus, it remains unclear whether reversal-learning deficits caused by noncontingent cocaine exposure are relevant to addiction. To test whether reversal learning deficits are caused by contingent cocaine exposure, we trained rats to self-administer cocaine, assessed cue-induced cocaine seeking in extinction tests after 1 and $30 \mathrm{~d}$ of withdrawal, and then tested for reversal learning more than a month later. We found robust time-dependent increases in cue-induced cocaine seeking in the two extinction tests (incubation of craving) and severe reversal-learning impairments.
\end{abstract}

Drug addicts make poor decisions. General decision-making deficits have been modeled in addicts and also in drug-exposed rats and monkeys using simple reversal-learning tasks and more complex "gambling" variants. In these tasks, subjects learn to associate different cues with different probabilities of reward and punishment; once subjects are responding appropriately, the meanings of the cues are reversed. Psychostimulant addicts and rats and monkeys exposed to cocaine have difficulty learning to stop responding to previously rewarded cues in these settings, despite adverse or undesirable consequences (Rogers et al. 1999; Grant et al. 2000; Bechara et al. 2001; Jentsch et al. 2002; Schoenbaum et al. 2004). In rats and monkeys, reversal-learning deficits have been demonstrated more than a month after cocaine treatment, and in rats these deficits have been linked to miscoding of associative information in orbitofrontal cortex and basolateral amygdala (Calu et al. 2005; Stalnaker et al. 2006b), areas implicated in reversal learning in normal animals (Rolls et al. 1994; Chudasama and Robbins 2003; Schoenbaum et al. 2003; Izquierdo et al. 2004; Stalnaker et al. 2006a). These observations have led to the suggestion that drug-induced changes in orbitofrontal processing might contribute to maladaptive decision-making in addicts (Jentsch and Taylor 1999; Volkow and Fowler 2000; Schoenbaum et al. 2006).

Findings from rats and monkeys are critical to this notion, because they show that reversal-learning deficits are not preexisting but instead are caused by drug exposure. However, these deficits have only been demonstrated after noncontingent experimenter-administered cocaine. It has been argued that to represent the human condition accurately, animal models of addic-

\footnotetext{
${ }^{5}$ Corresponding author.
}

E-mail schoenbg@schoenbaumlab.org; fax (410) 706-2512.

Article is online at http://www.learnmem.org/cgi/doi/10.1101//m.534807. tion must utilize self-administration procedures in which the drug is earned contingently during daily extended access sessions or over extended time periods (Wolffgramm et al. 2000; DerocheGamonet et al. 2004; Koob and Le Moal 2005). Indeed, contingent and noncontingent cocaine exposure induce different effects on brain neurochemistry and behavior in rats (Dworkin et al. 1995; Hemby et al. 1997; Crespo et al. 2001; Kiyatkin and Brown 2003; Lu et al. 2003; Kalivas and Hu 2006). As a result, it is not universally accepted that reversal-learning deficits demonstrated in these animal studies hold significance for understanding the behavior of addicts.

To explore whether long-lasting deficits in reversal learning occur after contingent exposure to cocaine, we trained rats to self-administer cocaine, tested for time-dependent increases in cue-induced cocaine seeking (i.e., incubation of craving; Grimm et al. 2001), and then assessed reversal learning using procedures identical to those we have used previously to test effects of noncontingent cocaine exposure and orbitofrontal lesions (Schoenbaum et al. 2003, 2004). All testing was conducted at the University of Maryland School of Medicine in accordance with University and NIH guidelines. Male Long-Evans rats $(n=7,300$ $350 \mathrm{~g}$, Charles River Labs) were implanted with jugular venous catheters, using published procedures (Lu et al. 2004a, 2005b). Silastic catheters were inserted into the jugular vein and passed subcutaneously to the top of the skull, where they were attached to a modified 22-gauge cannula (Plastics One) and mounted to the rat's skull with dental cement. After a one-week recovery period, these rats were trained to lever press for cocaine infusions, using published procedures Lu et al. 2004a,b; Lu et al. $2005 a, b)$. Briefly, self-administration was conducted in chambers from Coulbourn Instruments equipped with two levers. Pressing on the active lever resulted in infusion of cocaine- $\mathrm{HCl}(0.75 \mathrm{mg} /$ $\mathrm{kg} /$ infusion) accompanied by a 4 -sec tone-light cue, with a 40 -sec 

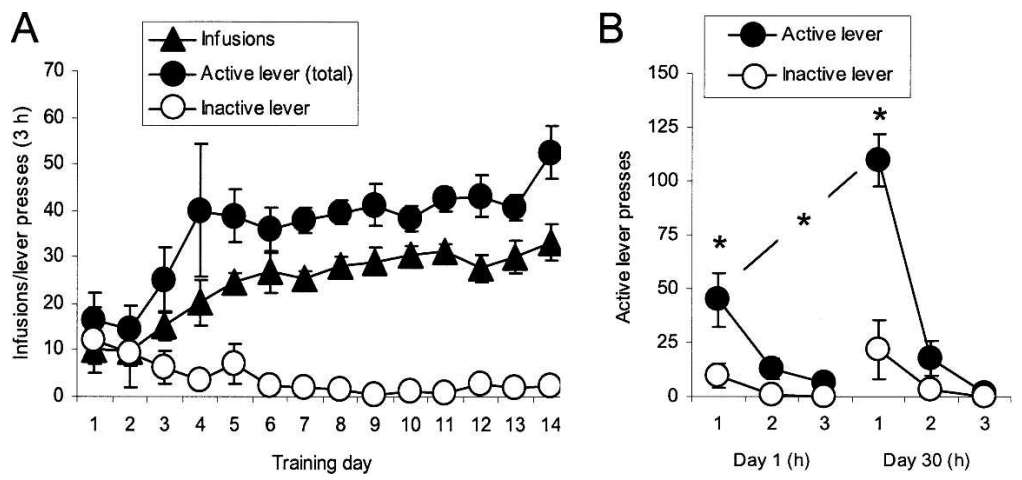

Figure 1. Cocaine self-administration and incubation of cocaine craving. (A) Mean \pm SEM number of cocaine infusions, responses (both infusion + timeout responses) on the active, cocaine lever, and responses on the inactive lever during the three $1-\mathrm{h}$ cocaine self-administration sessions. (B) Total responding per hour on the active and the inactive levers in the same rats during three 1-h extinction sessions conducted 1 and $30 \mathrm{~d}$ after cocaine self-administration training. $\left({ }^{*}\right)$ Different from Day 1 or from the inactive lever, $P<0.05$.

timeout period after each infusion. Pressing on the inactive lever had no programmed consequences. Sessions lasted $3 \mathrm{~h}$, with 15min timeout periods after each hour, and continued for 14 consecutive days.

As Figure 1A illustrates, the rats acquired cocaine selfadministration, as indicated by a significant interaction between lever and day in the analysis of active and inactive lever presses $\left(F_{(13,156)}=3.94, P<0.01\right)$ and a significant effect of training day for the number of infusions $\left(F_{(13,65)}=10.4, P<0.01\right)$. One and 30 $\mathrm{d}$ after the end of cocaine self-administration, we assessed lever pressing behavior during extinction sessions, using published procedures (Lu et al. 2004a, 2005b). These procedures were identical to those used in self-administration training except that pressing on the active lever did not result in drug infusion, though it did earn presentation of the tone-light cue that had been associated with drug infusion during training. Figure $1 \mathrm{~B}$ shows pressing on the active and inactive levers during these extinction sessions. A 3-factor ANOVA (lever $\times$ hour $\times$ day) showed that the rats pressed significantly more on the active lever on both days $\left(F_{(1,10)}=49.9, P<0.001\right)$ and significantly more on the active lever on day 30 than on day 1 , as indicated by a significant three-way interaction between lever, hour, and day $\left(F_{(2,20)}=6.4, P<0.01\right)$. A direct comparison of responding on the active lever on days 1 and 30 revealed a significant increase across days in the first hour $\left(F_{(1,10)}=19.1, P<0.01\right)$ and also over the entire 3 -h test period $\left(F_{(1,10)}=14.4, P<0.01\right)$.

Approximately one month after completion of late withdrawal (day 30) testing, the rats were water-deprived and then trained in an odor-guided go, no-go odor discrimination task. Odor discrimination testing was conducted in custom chambers that differed from those used for self-administration training. Procedures were identical to those we have used previously to assess the effects of lesions and passive exposure to cocaine (Schoenbaum et al. 2003, 2004). Briefly, rats sampled an odor on each trial and then had $3 \mathrm{sec}$ to decide whether to respond at a nearby fluid well; the "positive" odor predicted delivery of an appetitive $10 \%$ sucrose solution and the "negative" odor predicted delivery of an aversive $0.02 \mathrm{M}$ quinine solution. The rats were trained until they met a criterion of 18 correct responses in a moving block of 20 trials. After reaching criterion on several problems, they were tested on two serial reversals of the final problem. For this, the rats were first required to demonstrate retention of the original problem ( $\mathrm{S} 1+/ \mathrm{S} 2-)$, by meeting the behavioral criterion again, and then they were required to meet this same criterion again after the odor-outcome associations were switched $(\mathrm{S} 1-/ \mathrm{S} 2+)$. After the rats acquired the first reversal, retention of the reversed problem $(\mathrm{S} 1-/ \mathrm{S} 2+)$ was assessed the following day, after which the rats had to acquire a re-reversal of the problem $(\mathrm{S} 1+/ \mathrm{S} 2-)$. Note that rats also had to perform at $80 \%$ correct over a 60 trial block in order for reversals to proceed to further ensure accurate performance over a large number of trials. Their performance was compared to a set of male Long-Evans control rats ( $n=11,300-350 \mathrm{~g}$, Charles River Labs) that underwent discrimination and reversal testing using identical procedures in conjunction with a separate study (Stalnaker et al. 2006a). This group of rats did not receive jugular venous catheters or self-administration training but otherwise had handling, surgical experience (anesthesia, skull exposure), and training (discrimination training and also exposure to the selfadministration training environment for $1 \mathrm{~h}$ per day) that was similar to that of our experimental group. These rats acquired the problem to be reversed at the same rate as the rats trained to self-administer cocaine in the current study $(P>0.5)$ suggesting that training history, including instrumental training in the drug-treated rats several months earlier, did not interfere with discrimination performance prior to reversal. Moreover, as we will show next, their reacquisition rates were identical to those of the rats trained to self-administer cocaine.

Reversal performance of the rats in these two groups is illustrated in Figure 2. Rats that had been trained to self-administer cocaine required many more trials than controls to acquire the reversals. A 2-factor ANOVA (group $\times$ retention/reversal) confirmed this impression, revealing significant main effects of group $\left(F_{(1,15)}=16.7, P<0.001\right)$ and retention/reversal $\left(F_{(1,15)}=158.4\right.$, $P<0.001)$ and a significant interaction $\left(F_{(1,15)}=25.4, P<0.001\right)$. Subsequent contrasts showed no difference in performance during retention of the problems $(P>0.10)$, indicating that both groups learned the original discriminations to the same degree, but a significant impairment in acquiring the reversals $(P<0.001)$.

We have replicated our prior finding that cocaine exposure causes long-lasting impairments in reversal learning in rats (Schoenbaum et al. 2004). Previously, deficits were demonstrated in rats, approximately a month and a half after $14 \mathrm{~d}$ of exposure to experimenter-administered cocaine $(30 \mathrm{mg} / \mathrm{kg} / \mathrm{d}$, i.p.). In the present study, we show reversal-learning deficits in rats, $\sim 3 \mathrm{mo}$ after $14 \mathrm{~d}$ of exposure to self-administered cocaine $(18.4 \mathrm{mg} / \mathrm{kg} /$

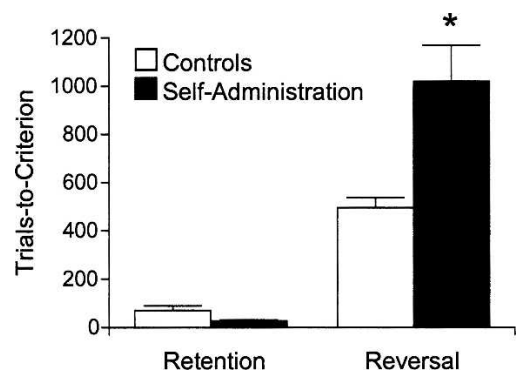

Figure 2. Long-term effects of cocaine self-administration on reversal learning. Shown are mean trials \pm SEM required by the rats in each group to twice retain and reverse a previously acquired odor discrimination problem. $\left(^{*}\right)$ Different from performance of controls, $P<0.05$. 
d, i.v.). Although deficits were demonstrated relative to controls that did not undergo the intravenous surgery or fluid infusion into the jugular vein, barring an unlikely long-lasting effect of these manipulations on reversal learning, these results indicate that contingent exposure to cocaine causes a reversal deficit in rats that is at least as severe and as long-lasting as that caused by noncontingent cocaine exposure (Schoenbaum et al. 2004). Furthermore, while comparisons across experiments should be done with caution, the magnitude of the reversal deficit caused by cocaine exposure ( $200 \%$ of controls in both this and our earlier experiment) is similar to that caused by orbitofrontal lesions in this task ( $200 \%$ of controls) (Schoenbaum et al. 2003). These results suggest that unique effects of contingent drug exposure cannot be the underlying basis of the decision-making deficits observed in addicts that are modeled by reversal learning. Thus, it should be possible to study the molecular and neurophysiological underpinnings of those deficits even after noncontingent drug exposure.

The reversal deficit was demonstrated in rats that exhibited a robust time-dependent increase in cue-induced cocaine seeking after withdrawal, a phenomenon termed incubation of cocaine craving (Grimm et al. 2001; Lu et al. 2004b). Reversal deficits are linked to orbitofrontal-amygdalar dysfunction (Rolls et al. 1994; Chudasama and Robbins 2003; Schoenbaum et al. 2003, 2006; Izquierdo et al. 2004; Stalnaker et al. 2006a), brain regions that show long-lasting effects of psychostimulants on neuroplasticity (Crombag et al. 2004; Goussakov et al. 2006). Notably, these same areas are also implicated in drug craving in humans and rats and in incubation of craving in rats (Volkow and Fowler 2000; Goldstein et al. 2001; Fuchs et al. 2004; Dom et al. 2005; Kalivas and Volkow 2005; Lu et al. 2005b). Since reversal learning was not assessed during early withdrawal from cocaine, the current report does not address whether or not these phenomena are directly related. It would be of great interest to determine whether the decision-making deficits demonstrated here reflect effects of cocaine on a similar neural substrate that mediates cocaine craving or incubation of craving.

\section{Acknowledgments}

This work was supported by R01-DA015718 (GS), T32-14074 (DC), and the Intramural Research Program of the National Institutes of Health, National Institute on Drug Abuse. We thank NIDA for providing the cocaine and Dr. Stephen Warrenburg at International Flavors and Fragrances for providing the odor compounds.

\section{References}

Bechara, A., Dolan, S., Denburg, N., Hindes, A., Andersen, S.W., and Nathan, P.E. 2001. Decision-making deficits, linked to a dysfunctional ventromedial prefrontal cortex, revealed in alcohol and stimulant abusers. Neuropsychologia 39: 376-389.

Calu, D.J., Stalnaker, T.A., Roesch, M.R., Franz, T.M., and Schoenbaum, G. 2005. Basolateral amygdala generates abnormally persistent representations of predicted outcomes and cue value after cocaine exposure. Society for Neuroscience Abstracts 35: 112.1.

Chudasama, Y. and Robbins, T.W. 2003. Dissociable contributions of the orbitofrontal and infralimbic cortex to pavlovian autoshaping and discrimination reversal learning: Further evidence for the functional heterogeneity of the rodent frontal cortex. J. Neurosci. 23: 8771-8780.

Crespo, J.A., Manzanares, J., Olivia, J.M., Corchero, J., Palomo, T., and Ambrosio, E. 2001. Extinction of cocaine self-administration produces a differential time related regulation of proenkephalin gene expression in rat brain. Neuropsychopharmacology 25: 185-194.

Crombag, H.S., Gorny, G., Li, Y., Kolb, B., and Robinson, T.E. 2004. Opposite effects of amphetamine self-administration experience on dendritic spines in the medial and orbital prefrontal cortex. Cereb. Cortex 15: 341-348.

Deroche-Gamonet, V., Belin, D., and Piazza, P.V. 2004. Evidence for addiction-like behavior in the rat. Science 305: 951-953.
Dom, G., Sabbe, B., Hulstijn, W., and Van Den Brink, W. 2005. Substance use disorders and the orbitofrontal cortex. Br. J. Psychiatry 187: 209-220.

Dworkin, S.I., Mirkis, S., and Smith, J.E. 1995. Response-dependent versus response-independent presentation of cocaine: Differences in the lethal effects of the drug. Psychopharmacology 117: 262-266.

Fuchs, R.A., Evans, K.A., Parker, M.P., and See, R.E. 2004. Differential involvement of orbitofrontal cortex subregions in conditioned cue-induced and cocaine-primed reinstatement of cocaine seeking in rats. J. Neurosci. 24: 6600-6610.

Goldstein, R.Z., Volkow, N.D., Wang, G.J., Fowler, J.S., and Rajaram, S. 2001. Addiction changes orbitofrontal gyrus function: involvement in response inhibition. Neuroreport 12: 2595-2599.

Goussakov, I., Chartoff, E.H., Tsvetkov, E., Gerety, L.P., Meloni, E.G., Carlezon, W.A.J., and Bolshakov, V.Y. 2006. LTP in the lateral amygdala during cocaine withdrawal. Eur. J. Neurosci. 23: 239-250.

Grant, S., Contoreggi, C., and London, E.D. 2000. Drug abusers show impaired performance in a laboratory test of decision making. Neuropsychologia 38: 1180-1187.

Grimm, J.W., Hope, B.T., Wise, R.A., and Shaham, Y. 2001. Incubation of cocaine craving after withdrawal. Nature 412: 141-142.

Hemby, S.E., Co, C., Koves, T.R., Smith, J.E., and Dworkin, S.I. 1997. Differences in extracellular dopamine concentrations in the nucleus accumbens during response-dependent and response-independent cocaine administration in the rat. Psychopharmacology 133: 7-16.

Izquierdo, A.D., Suda, R.K., and Murray, E.A. 2004. Bilateral orbital prefrontal cortex lesions in rhesus monkeys disrupt choices guided by both reward value and reward contingency. J. Neurosci. 24: 7540-7548.

Jentsch, J.D. and Taylor, J.R. 1999. Impulsivity resulting from frontostriatal dysfunction in drug abuse: Implications for the control of behavior by reward-related stimuli. Psychopharmacology 146: $373-390$.

Jentsch, J.D., Olausson, P., De La Garza, R., and Taylor, J.R. 2002. Impairments of reversal learning and response perseveration after repeated, intermittent cocaine administrations to monkeys. Neuropsychopharmacology 26: 183-190.

Kalivas, P.W. and Hu, X.T. 2006. Exciting inhibition in psychostimulant addiction. Trends Neurosci. 29: 610-616.

Kalivas, P.W. and Volkow, N.D. 2005. The neural basis of addiction: A pathology of motivation and choice. Am. J. Psychiatry 162: 1403-1413.

Kiyatkin, E.A. and Brown, P.L. 2003. Fluctuations in neural activity during cocaine self-administration: clues provided by brain thermorecording. Neuroscience 116: 525-538.

Koob, G.F. and Le Moal, M. 2005. Plasticity of reward neruocircuitry and the 'dark side' of drug addiction. Nat. Neurosci. 8: 1442-1444.

Lu, L., Grimm, J.W., Shaham, Y., and Hope, B.T. 2003. Molecular neuroadaptations in the accumbens and ventral tegmental area during the first 90 days of forced abstinence from cocaine self-administration in rats. J. Neurochem. 85: 1604-1613.

Lu, L., Grimm, J.W., Dempsey, J., and Shaham, Y. 2004a. Cocaine seeking over extended withdrawal periods in rats: Different time courses of responding induced by cocaine cues versus cocaine priming over the first 6 months. Psychopharmacology 176: 101-108.

Lu, L., Grimm, J.W., Hope, B.T., and Shaham, Y. 2004b. Incubation of cocaine craving after withdrawal: A review of preclinical data. Neuropharmacology (Suppl 1) 47: 214-226.

Lu, L., Dempsey, J., Shaham, Y., and Hope, B.T. 2005a. Differential long-term neuroadaptations of glutamate receptors in the basolateral and central amygdala after withdrawal from cocaine self-administration in rats. J. Neurochem. 94: 161-168.

Lu, L., Hope, B.T., Dempsey, J., Liu, S.Y., Bossert, J.M., and Shaham, Y. 2005b. Central amygdala ERK signaling pathway is critical to incubation of cocaine craving. Nat. Neurosci. 8: 212-219.

Rogers, R.D., Everitt, B.J., Baldacchino, A., Blackshaw, A.J., Swainson, R., Wynne, K., Baker, N.B., Hunter, J., Carthy, T., Booker, E., et al. 1999. Dissociable deficits in the decision-making cognition of chronic amphetamine abusers, opiate abusers, patients with focal damage to prefrontal cortex, and tryptophan-depleted normal volunteers: Evidence for monoaminergic mechanisms. Neuropsychopharmacology 20: 322-339.

Rolls, E.T., Hornak, J., Wade, D., and McGrath, J. 1994. Emotion-related learning in patients with social and emotional changes associated with frontal lobe damage. J. Neurol. Neurosurg. Psychiatr. 57: 1518-1524.

Schoenbaum, G., Setlow, B., Nugent, S.L., Saddoris, M.P., and Gallagher, M. 2003. Lesions of orbitofrontal cortex and basolateral amygdala complex disrupt acquisition of odor-guided discriminations and reversals. Learn. Mem. 10: 129-140.

Schoenbaum, G., Saddoris, M.P., Ramus, S.J., Shaham, Y., and Setlow, B. 2004. Cocaine-experienced rats exhibit learning deficits in a task 


\section{Calu et al.}

sensitive to orbitofrontal cortex lesions. Eur. J. Neurosci. 19: 1997-2002.

Schoenbaum, G., Roesch, M.R., and Stalnaker, T.A. 2006. Orbitofrontal cortex, decision-making, and drug addiction. Trends Neurosci. 29: $116-124$.

Stalnaker, T.A., Franz, T.M., and Schoenbaum, G. 2006a. Lesions of basolateral amygdala eliminate the reversal impairment caused by orbitofrontal cortex lesions. Society for Neuroscience Abstracts 36: 573.18 .

Stalnaker, T.A., Roesch, M.R., Franz, T.M., Burke, K.A., and Schoenbaum, G. 2006b. Abnormal associative encoding in orbitofrontal neurons in cocaine-experienced rats during decision-making. Eur. J. Neurosci. 24: 2643-2653.

Volkow, N.D. and Fowler, J.S. 2000. Addiction, a disease of compulsion and drive: involvement of orbitofrontal cortex. Cereb. Cortex 10: $318-325$.

Wolffgramm, J., Galli, G., Thimm, F., and Heyne, A. 2000. Animal models of addiction: models for therapeutic strategies? J. Neural Transm. 107: 649-668.

Received January 13, 2007; accepted in revised form March 6, 2007. 


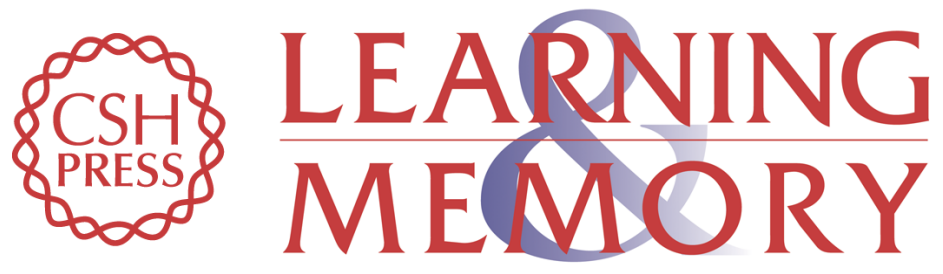

\section{Withdrawal from cocaine self-administration produces long-lasting deficits in orbitofrontal-dependent reversal learning in rats}

Donna J. Calu, Thomas A. Stalnaker, Theresa M. Franz, et al.

Learn. Mem. 2007, 14:

Access the most recent version at doi:10.1101//m.534807

References This article cites 35 articles, 7 of which can be accessed free at:

http://learnmem.cshlp.org/content/14/5/325.full.html\#ref-list-1

License

Email Alerting Receive free email alerts when new articles cite this article - sign up in the box at the Service top right corner of the article or click here. 